\title{
Comparison between High Frequency and Low Frequency Portable Transcutaneous Electrical Nerve Stimulation in Patients with Knee Osteoarthritis: A prospective Randomized Study
}

\author{
Charles Ang Poh Thean ${ }^{1}$, Mohd Shukrimi Awang ${ }^{2}$, Satriya Sabir Husin Athar ${ }^{3}$ \\ ${ }^{1}$ Department of Orthopaedics, Traumatology and Rehabilitation, International \\ Islamic University Malaysia Medical Center \\ ${ }^{2}$ Department of Orthopaedics, Traumatology and Rehabilitation, Kulliyyah of \\ Medicine, International Islamic University Malaysia \\ ${ }^{3}$ Department of Orthopaedics, Hospital Selayang
}

\section{Presenter: Charles Ang Poh Thean}

Introduction: Knee osteoarthritis has been an increasing problem in the society causing significant morbidity. The current trend of medical treatment is moving from pharmacological to non pharmacological methods of treatment thereby reducing the side effect and the cost burden of the pharmacological means. TENS therapy has been studied in the past to treat pain knee osteoarthritis related pain, however that is a mix report on its success. After careful understanding and various literature review on the mechanism of TENS therapy, the author narrowed down the success of the therapy may be frequency related (inappropriate frequency used). Materials and Methods: The first 100 patient who attended the outpatient department diagnosed with knee osteoarthritis (based on Kellgren and Lawrence grade 2-4) who willingly consented, were selected and randomly allocated to two arms (high- frequency and Low- frequency). A baseline score was taken based on the Oxford knee score, WOMAC, Lesquene index and Visual Analog Score. They were followed up on the $1^{\text {st }}$ and $3^{\text {rd }}$ month for assessment. Results: There was a significant improvement in the activities of daily living in the high frequency group $(p<0.001)$ as compared to the low frequency $(p>0.95)$. However, both groups showed significant improvement in the Visual Analog score with no statistical difference. Conclusion: TENS therapy is a good non-pharmacological alternative to treat knee osteoarthritis, provided the right method and frequency is used. 